\title{
TITLE:
}

\section{Identification of the chemical states of phosphorus in atmospheric aerosols by XANES spectrometry}

$\operatorname{AUTHOR}(S)$ :

Tohno, Susumu; Kawai, Jun; Kitajima, Yoshinori

\section{CITATION:}

Tohno, Susumu ...[et al]. Identification of the chemical states of phosphorus in atmospheric aerosols by XANES spectrometry. Journal of Synchrotron Radiation 2001, 8(2): 958-960

\section{ISSUE DATE:}

2001-03-01

URL:

http://hdl.handle.net/2433/237637

RIGHT:

(C) 2001 International Union of Crystallography 


\section{Identification of the chemical states of phosphorus in atmospheric aerosols by XANES spectrometry}

\author{
Susumu Tohno ${ }^{a \star}$, Jun Kawai ${ }^{b}$, Yoshinori Kitajima ${ }^{c}$ \\ ${ }^{a}$ Department of Socio-Environmental Energy Science, \\ Graduate School of Energy Science, Kyoto University, Uji, \\ Kyoto 611-0011, Japan, ${ }^{b}$ Department of Materials \\ Engineering, Graduate School of Engineering, Kyoto \\ University, Sakyo-ku, Kyoto 606-8501, Japan, 'KEK-PF, \\ Oho 1-1, Tsukuba, Ibaraki 305-0801, Japan. E-mail: \\ tohno@energy.kyoto-u.ac.jp
}

Depth selective XAFS spectrometry was applied to determine the chemical states of phosphorus in atmospheric aerosols. Atmospheric aerosols were collected on aluminum foils and polyethylene films using a 4-stage cascade impactor and a 12stage low pressure Andersen sampler, respectively. Samplings were performed at Uji (urban area) and Sakurajima (near a volcano). We measured X-ray fluorescence yield (XFY) and total electron yield (sample current) simultaneously to obtain the $\mathrm{X}$-ray absorption near edge structure (XANES) spectra of the atmospheric aerosols. X-ray absorption in the vicinities of $\mathrm{P}$ Kedges was measured on the beamline BL-11B at the Photon Factory, High Energy Accelerator Research Organization, Tsukuba, Japan. The Sakurajima aerosol samples showed only a $\mathrm{P}^{5+}$ peak and the peak was remarkable in coarse mode. In case of the Uji samples, the $\mathrm{P}^{5+}$ peak was dominant and a slight $\mathrm{P}^{3+}$ peak was detected for sample current measurement.

\section{Keywords: atmospheric aerosol, phosphorous, XANES}

\section{Introduction}

Chemical composition of atmospheric aerosols is one of the key parameters to understand their sources, environmental effects and processing in the atmosphere. Elemental or ionic concentrations of the size-segregated atmospheric aerosols have been measured by conventional analytical techniques such as PIXE (Particle Induce X-ray Emission) or IC (Ion Chromatography). However, their chemical states cannot be assessed with those methods. and few study has been carried out on the measurement of their chemical states. We have applied the depth selective XAFS spectrometry developed by Kawai (1995) to determine the chemical states of sulfur and silicon in atmospheric aerosols (Tohno, et al, 1998).

Phosphorous in atmospheric aerosols comes primarily from the ocean, the earth's crust and the emissions due to human activities, etc. (Chen et al., 1985). Aerosol transport of phosphorus from the continents through the atmosphere to the oceans is an important process in the biogeochemical cycling. Since extremely trace amount of phosphorous is contained in atmospheric aerosols, there have been no reports on the chemical states of phosphorous in the aerosols. We compare P K-edge XANES spectra for atmospheric aerosols and soils with SR from the viewpoint of source apportionment in two distinct sites (urban aerosol and volcanic aerosol).

\section{Experimental}

2.1 Aerosol and soil sampling
At Uji (urban area) atmospheric aerosols were collected with a 12-stage low-pressure Andersen sampler equipped with a backup filter which separates particles into the size ranges from 0.05 to greater than $11 \mu \mathrm{m}$ aerodynamic diameter. Polyethylene sheets were used as sampling substrates on the impaction stages. As a backup filter, a $0.4 \mu \mathrm{m}$ pore size Nuclepore filter was used. The impactor was operated at a constant flow rate of $24.5 \mathrm{~L} / \mathrm{min}$ and the sampling time was one day. Coarse and fine fractions of atmospheric aerosols were separately collected using two-stage filter packs ( 8 and $0.4 \mu \mathrm{m}$ Nuclepore filter) with an effective cutoff diameter of $1 \mu \mathrm{m}$. Sampling was made on the roof $(17 \mathrm{~m}$ height) of the main building of Kyoto University, Uji campus.

Coarse fractions of atmospheric aerosols were collected on aluminum foils using a 4-stage cascade impactor at the Harutayama observatory of Disaster Prevention Research Institute, Kyoto University in Sakurajima where an active volcano locates.

Soil samples were also collected from the surface ground near the both sampling sites.

\subsection{Sample preparation}

Aerosol samples collected on the polyethylene sheets and the Nuclepore filters were extracted in pure water with an ultrasonic bath. The extracted solutions were dropped on aluminum foils and dried. The samples collected on aluminum foils were directly subjected to X-ray absorption measurement without any treatment. Soil samples were taken by a spatula and put on aluminum foil, and then ethanol was dropped on the samples to disperse. The samples were dried and introduced into the experimental chamber.

\section{$2.3 X$-ray absorption measurement}

P K-edge XANES spectra were measured at BL-11B equipped with double-crystal $\mathrm{Ge}(111)$ monochromator at the Photon Factory, High Energy Accelerator Research Organization, Tsukuba, Japan. Figure 1 shows a schematic illustration of the experimental system. We measured X-ray fluorescence yield (XFY) and total electron yield (sample current) simultaneously to obtain the X-ray absorption near edge structure (XANES) spectra of the atmospheric aerosols. The positron storage ring current was $220-440 \mathrm{~mA}$ during the measurement and the X-ray intensity was in the order of $10^{9}$ photons/s on the sample.

The measurements were conducted in a vacuum chamber $\left(\sim 10^{-6}\right.$ Torr). Monochromator scan range was $2120-2200 \mathrm{eV}$ with $0.2 \mathrm{eV}$ steps and the dwell time for one channel was $1-4 \mathrm{~s}$. The X-ray size at the sample was defined by an approximately 2 $\times 2 \mathrm{~mm}$ slit. The incident X-ray intensity was recorded by measuring the copper mesh current as shown in Fig. 1. The

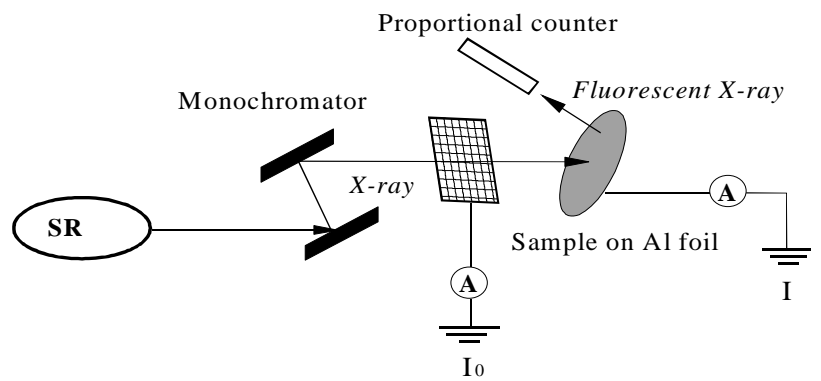

Figure 1

Schematic illustration of the experimental setup on BL-11B at Photon Factory, High Energy Accelerator Research Organization, Tsukuba, Japan. 


\section{environmental, earth and planetary science}

angle between the incident X-ray and the proportional counter was about $90^{\circ}$. The output signal of the counter was amplified and then a single channel analyzer was used to select the $\mathrm{P} K \alpha$ signal. XANES spectrum of aluminum foil without any sample was measured as a blank and no phosphorous peak was detected. - There exists very minute amount of phosphorous in atmospheric aerosols and the obtained spectrum is noisy. Then the spectra of atmospheric aerosols were obtained as a sum of ten scans.

\section{Results and discussion}

$\mathrm{P}$ K-edge spectra of $\mathrm{BP}$ and $\mathrm{Na}_{2} \mathrm{HPO}_{4}$ powders were measured as standards and monochromator calibration was carried out with the first intense peak $\left(\mathrm{P}^{5+}\right)$ in the phosphorous K-edge absorption spectrum of $\mathrm{Na}_{2} \mathrm{HPO}_{4}$ powder. Figure 2 shows the obtained $\mathrm{P} \mathrm{K}$ edge spectra. Phosphorous $\mathrm{K}$ absorption peaks of $\mathrm{P}^{3+}$ and $\mathrm{P}^{5+}$ lie at $2147 \mathrm{eV}$ and $2151 \mathrm{eV}$, respectively.

Figure 3 shows the P K-edge spectra of atmospheric aerosols sampled at Sakurajima and a single peak corresponding to $\mathrm{P}^{5+}$ was observed. The $\mathrm{P}^{5+}$ peak was found for both XFY and sample current in case of the samples collected at the stage 2 of the impactor. However, with a decrease in particle size, XFY peak was not detected and the peak was found only for sample current. Since the sample current method is more surface sensitive than the XFY method, the $\mathrm{P}^{5+}$ phosphorous atoms were more dominant on the particle surface with decrease of the size. For the fine aerosols collected at the impactor stage 4, no clear peak was observed. This means that phosphorous was hardly present in the Sakurajima aerosols of fine mode. Figure 4 indicates P Kedge spectra of Sakurajima soil samples collected near the aerosol sampling sites. An identical $\mathrm{P}^{5+}$ peak of the aerosol

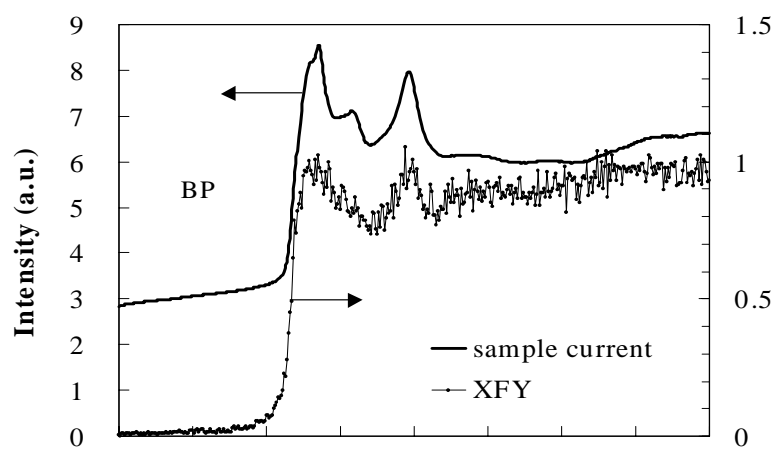

212021302140215021602170218021902200

Energy (eV)

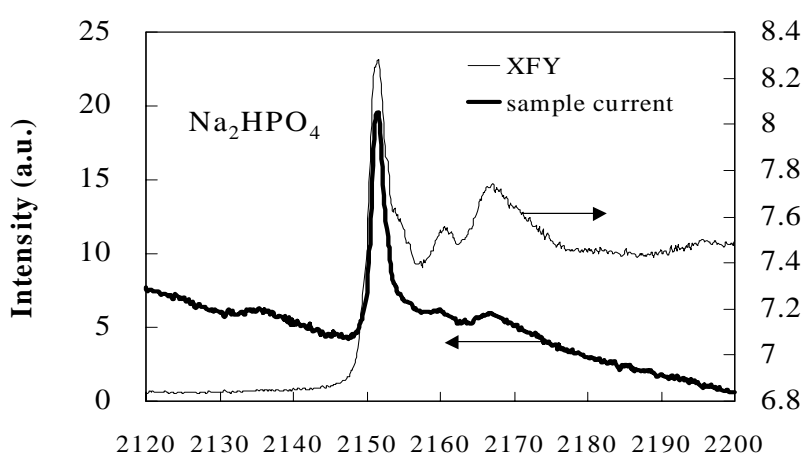

Energy (eV)

Figure 2.

P K-edge spectra of phosphorus standard samples

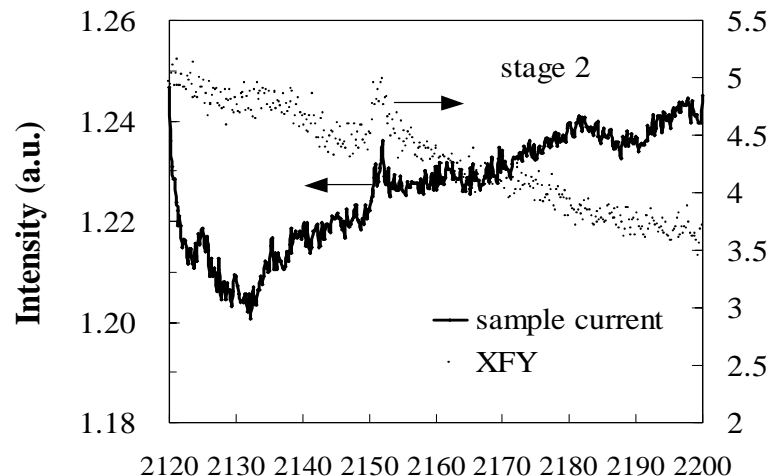

Energy (eV)

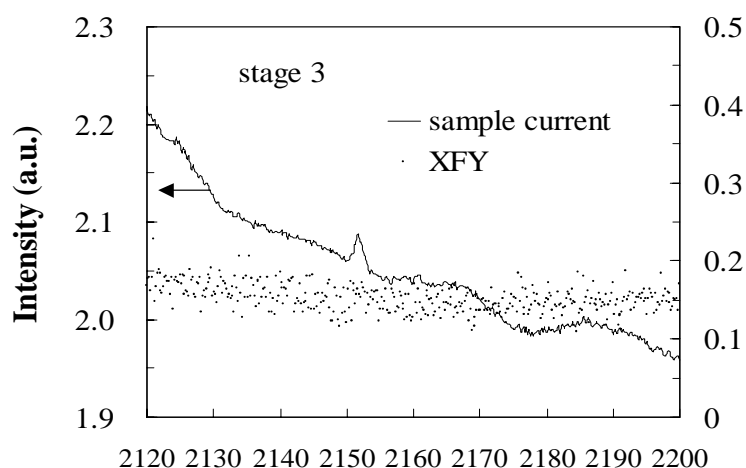

Energy (eV)

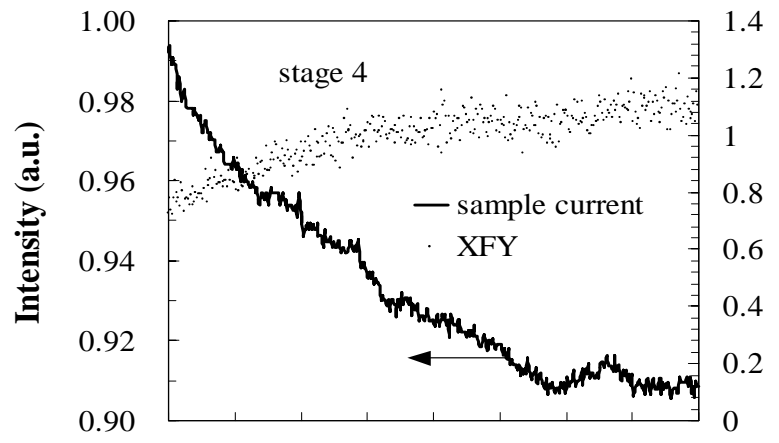

212021302140215021602170218021902200

Energy (eV)

Figure 3.

P K-edge spectra of atmospheric aerosols sampled on each stage of a cascade impactor at Sakurajima on March 1998. Effective cut-off diameters of the stage 2, 3 and 4 are 4.6, 2.1 and $1.0 \mu \mathrm{m}$, respectively

samples was detected for the soil samples. X-ray diffraction study of Sakurajima ash fall indicates that $\mathrm{P}_{2} \mathrm{O}_{5}$ is the major components of phosphorous compounds. Thus, phosphorous in Sakurajima aerosol is considered to arise mainly from the surrounding soil or ash fall, that is, natural sources.

Coarse aerosols sampled at Uji showed $\mathrm{P}^{5+}$ peak in the XANES spectra for both sample current and XFY measurements, while two (strong and extremely weak) peaks were obtained for aerosols in fine mode as shown in Fig. 5. The strong peak corresponds to $\mathrm{P}^{5+}$ and the weak peak is at lower energy than the strong one. Comparison of the reference spectra $\left(\mathrm{Na}_{2} \mathrm{HPO}_{4}\right.$ and 


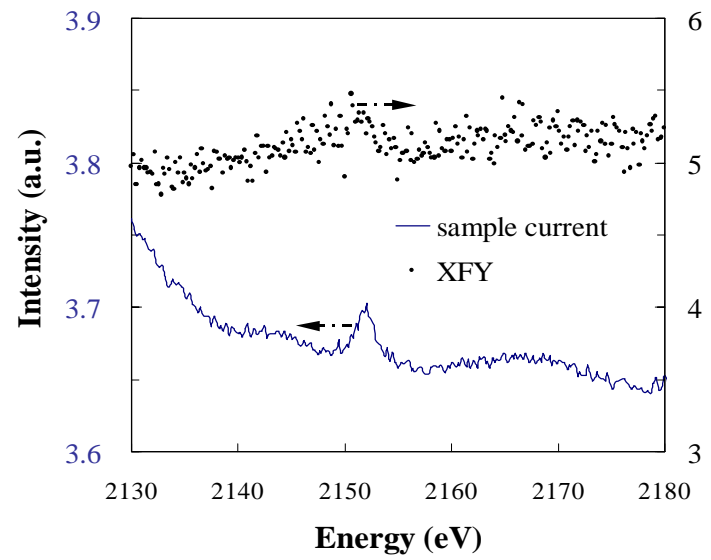

Figure 4

P K-edge spectra of soil samples collected near Harutayama observatory at Sakurajima.

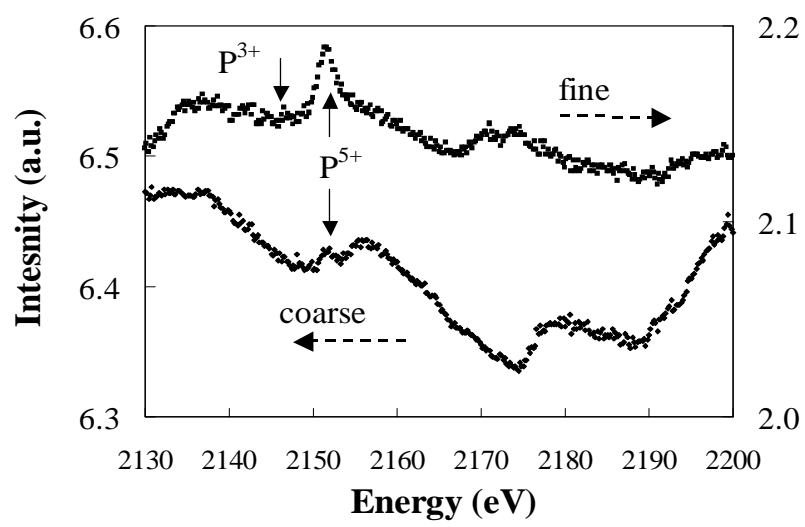

Figure 5 .

P K-edge spectra of atmospheric aerosols in coarse and fine mode at Uji on December 1998. The spectra were obtained from sample current measurements.

$\mathrm{BP})$ suggests that this weak peak is attributed to $\mathrm{P}^{3+}$. For coarse aerosols, extremely weak $\mathrm{P}^{3+}$ peak seems to exist, but the peak is comparable to noise level. Only a $\mathrm{P}^{5+}$ peak was found for $\mathrm{Uji}$ soil samples. Crustal or soil materials are usually in the coarse aerosol fraction (Seinfeld \& Pandis, 1998). Complete separation of coarse and fine particles by two stage filter packs is not achieved and coarse particles are partly collected in fine filter pack, and vice versa. Therefore some aerosols in the fine mode contain $\mathrm{P}^{5+}$ from soil source source and part of aerosols in the coarse mode has the possibility to contain trace quantity of $\mathrm{P}^{3+}$.

We also sampled atmospheric aerosols at Uji during Kosa (yellow sand) event with a low-pressure Andersen sampler. A single $\mathrm{P}^{5+}$ peak was found in the XANES spectra for the coarse particles and was clearer than that in usual urban aerosols in Uji. Figure 6 shows the P K-edge spectra for the Kosa aerosol samples collected on a Backup filter (less than $0.05 \mu \mathrm{m}$ in aerodynamic diameter). $\mathrm{P}^{5+}$ peak was dominant and slight $\mathrm{P}^{3+}$ peak was detected for sample current measurement. P K-edge spectra of China loess sample showed only a $\mathrm{P}^{5+}$ peak. The origin of phosphorous in ultrafine particles is not from crustal or soil materials, but is from the combustion of fuel or garbage like via vapor condensation process, that is, anthropogenic sources.

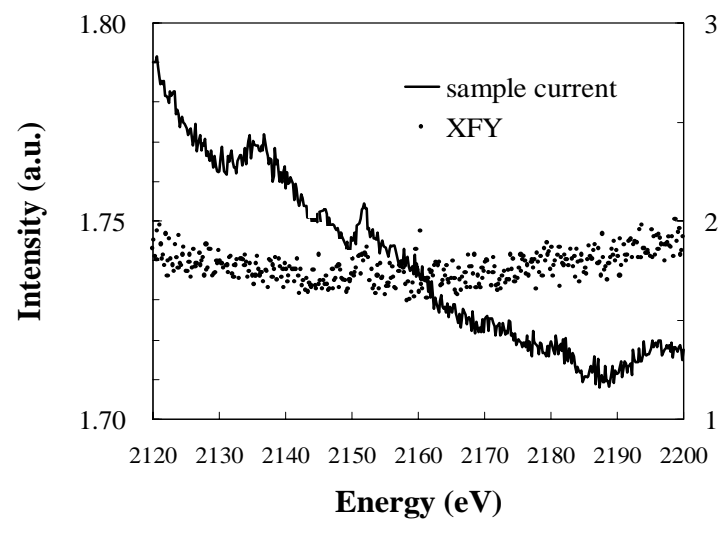

Figure 6.

P K-edge spectra of atmospheric aerosols collected on a Backup filter at Uji during Kosa event.

$\mathrm{P}^{3+}$ peak is unique in fine mode of urban aerosols and has the possibility to be used as an index of anthropogenic origin. Coagulation of ultrafine particles containing $\mathrm{P}^{3+}$ and coarse particles results in the possible $\mathrm{P}^{3+}$ peak in the XANES spectra of the coarse particles in Uji and the peak may be found in Fig. 5. Further work is required to specify the anthropogenic origin.

This work has been performed under the approval of the Photon Factory Program Advisory Committee PF-PAC No. 98-G316. The authors express their thanks to Dr. K. Yamamoto for his samplings at Sakurajima.

\section{References}

Chen, L., Arimoto, R. \& Duce, R.A. (1985). Atmos. Environ. 19, 779787.

Kawai, J., Hayakawa, S., Esaka, F., Zheng, S., Kitajima, Y., Maeda, K., Adachi, H., Gohshi, Y. \& Furuya, K. (1995) Anal. Chem., 24, 15261529.

Seinfeld, J.J. \& Pandis, S.N. (1998) Atmospheric Chemistry and Physics, John Wiley \& Sons, Inc.

Tohno, S., Kawai, J., Chatani, S., Yamamoto, T., Kitajima, Y., Yamamoto, K. Kitamura, Y. \& Kasahara, M. (1998) J. Aerosol Sci. 32, S235-S236. 